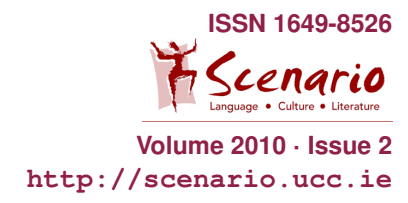

Review

\title{
Classics in Miniature - QUIXOTE. A Film by Steven Ritz-Barr
}

\section{Stephen Boyd}

Quixote is the second in the California-based Classics in Miniature series of short film versions of literary classics performed by puppets. The first film, Faust, was launched in 2008, and reviewed by Joachim Beug in Scenario 2008, Issue 2 (see http://publish.ucc.ie/scenario/2008/02/beug/09/en).

The double challenge of condensing a work as vast as Cervantes's Don Quijote - the text runs to about a thousand pages in most standard-format editions into a film which lasts a half an hour and in which all the roles are performed by puppets is obviously very great, and all the more so when one considers that, according to the project website (www.classicsinminiature.com), this film, like the others in the series, is aimed at the "educational market (from age 12 through university) and to the general public", and is "for everyone - young and old, cynical and romantic." The implication that the creators of the series are conscious of the risks of over-simplification and sentimentalizing - risks which they might afford to incur if young children were, exclusively, their target audience - seems clear. Equally, it seems clear that they aim to communicate the essence of the original works not just to people who may never have read them but also to those who have. To do so successfully, of course, requires familiarity with the texts, and, to some extent, with the traditions of commentary on them. The focus of this review will be the interpretation of Don Quijote that this short film proposes.

Cervantes's great novel (published in two parts in 1605 and 1615) has inspired a vast number of other works in almost every conceivable medium: books; films; paintings; cartoons; comics; ballets; operas; musicals; video games. Generations have found humour, pathos and puzzlement in the figure of the tall, bony, aging, unmarried, nouveau-pauvre Spanish country gentleman who wanders the arid wastes of his native La Mancha looking for adventure and wrongs to right, deludedly imitating the knight protagonists of the tales of chivalry that he has been obsessively reading for years. Equally, they have found his friendship with his sidekick and supposed squire, the fat, venal, gullible and cunning peasant farmer, Sancho Panza, both intriguing and amusing. It appears that seventeenth-century readers in Spain and elsewhere regarded Don Quijote as nothing more than an amusing idiot. During the Romantic period, however, he came to be seen as a sad and noble dreamer, a Christ-like innocent whose idealistic pursuit of love and justice clashes tragically with the materialism and moral coarseness of the real world. At the level of popular 
culture, this interpretation of Cervantes's protagonist is well represented by, for example, Dale Wasserman's 1965 musical, Man of La Mancha, with its 'Impossible Dream' theme song. For the last number of decades (since about 1980), while not completely discarding it, there has been a concerted effort in the world of Cervantes scholarship to liberate Don Quijote and Don Quijote from the distortions of that 'Romantic Interpretation'. ${ }^{1}$ This reviewer had half expected that Ritz-Barr's Quixote might follow in that tradition, but was pleasantly surprised to find that, in fact, it succeeds very well in bringing out the disconcerting ambiguities of Cervantes's original character and book. First, Eugene Seregin (the designer and maker of the puppets) has succeeded in creating a Don Quijote marionette whose large, staring, heavily-lidded eyes communicate an expression that is simultaneously sad, genteel and vacant. The character's voice (read by Michael York) is, appropriately, a rather tired, English-accented, aristocratic one. This makes him sound, so far, like the "knight of the sad countenance" of Romantic tradition. Such, however, is really not the case, and that has a lot to do with the episodes that Ritz-Barr has selected from the original text and with the details from those episodes on which he has chosen to focus. Cervantes's Don Quijote has 126 chapters and features a vast array of characters and incidents. Obviously, it would be impossible for even a feature-length film to incorporate all of them. This short film reduces the story to (effectively) ten scenes or 'chapters'. One would expect any version with pretensions to fidelity, however condensed, to respect the fundamentally tripartite and circular pattern of Don Quijote's journey: the chivalric delusion that leads to his abandonment of his home; his adventures as a 'knight'; his disillusioned return home. Quixote is structured in accordance with that pattern. One would expect to find scenes that explain the origins and form of Don Quijote's madness. Again, that expectation is met. Thus, its first 'chapter' (the longest single one) shows Alonso Quijano's reinvention of himself as Don Quijote, of his thin old nag, as the war horse, Rocinante, and of a gap-toothed local farm girl, as his lady love, Dulcinea del Toboso. One would expect to find scenes that encapsulate the typical pattern of his adventures. Again, that expectation is fulfilled. Thus, 'Chapter 3', 'Merchants by the Creek' and 'Chapter 6', 'The Flock of Sheep' clearly represent the multiplicity of incidents in which Don Quijote suffers the (usually humiliating and physically painful) consequences of his mistaking real-life people and things for people and things from the world of chivalric fantasy. Any version might be expected to feature the most famous (indeed, 'iconic') episode of this kind: Don Quijote's attack on the windmills. It is present as 'Chapter 5'. Finally, one might expect to find some representation of the attempts of Don Quijote's family and friends to rescue him from his 'illness'. Perhaps not surprisingly - since it constitutes the single most dramatic instance of this, and, with its echoes of the procedures of the Inquisition, serves to suggest something of the cultural context of Cervantes's Spain - the episode in which Don Quijote's housekeeper and niece burn his

\footnotetext{
${ }^{1}$ See Bibliography for details of Anthony Close's classic study of the Romantic tradition of interpretation.
} 
books appears as 'Chapter 4', 'Book Burning'.

Cervantes presents his character as a fundamentally good man, but he also offers occasional glimpses of less attractive sides of his personality, such as his vanity. At certain moments, too, the seriously destructive impact of some his interventions in the lives of others is allowed to emerge starkly, and the prevailing mood of comedy and laughter suddenly darkens over. Typically, 'Romantic' readings and versions of the text ignore or avoid these moments. It is particularly to the credit of Ritz-Barr's Quixote that it actively embraces them. (One suspects that the film's 'Don Quixote Consultant', Dr Howard Mancing, Professor of Spanish at Purdue University and a distinguished Cervantes scholar, may have supplied some very good advice.) 'Chapter 6', 'The Flock of Sheep' is a good example. It is based on an episode (Don Quijote I, 18) in which Don Quijote ferociously attacks a flock of sheep which he imagines to be a hostile army on the march. The attendant shepherds are forced to bring him to the ground with stones fired from their slings, but not before he has killed at least seven of their animals. In the film, the puppet Don Quijote is shown determinedly spearing a puppet sheep. This is followed by a close-up shot that shows the animal transfixed and bleating on the end of his lance as he rides about in the dust of the supposed battlefield. We hear the stones fired by the young shepherd hitting his body with a convincing thwack, and we are made to feel that he is justified to shout "Monster" at the madman he has knocked to the ground. The scene concludes with an over-head shot of Don Quijote lying spread-eagled on the ground surrounded by the fluffy, red-stained, corpses of three puppet sheep that he has killed. This is (deliberately) not the stuff of puppet theatre for young children, but its combination of innocent-looking figures and violence serves as an effective analogue of Cervantes's persistent and elusive blending of the comic and the serious.

In Cervantes's text, Don Quijote is eventually defeated in a jousting match to which he has been challenged by a much younger and stronger neighbour, who has disguised himself as a knight. Each man has promised, if vanquished, to do whatever the victor requires of him. Don Quijote is made to agree to return home and never again ride forth as a knight. In great dejection, he fulfils his promise. On arriving home, he falls into a coma, and then emerges from it having mysteriously recovered his sanity and his awareness of being Alonso Quijano. Very shortly afterwards, he dies. In Quixote, his decision to return to home is prompted by the recovery of his sanity and - no doubt appropriately in such a short film - he does not die. In fact, Ritz-Barr ingeniously exploits both parts of another deeply humiliating encounter between Don Quijote and a young man in Part I of the original text (Chapters 4 and 31) to provide his film with an ending that is psychologically convincing, aesthetically satisfying and faithful to the spirit of the original. 'Chapter 2', 'Boy and Master', is based on Don Quijote's first adventure as a newly dubbed knight, and it provides the first indication of the writer-producer's determination (discussed above) to confront the darker aspects of the character and the book. Don Quijote forces a farmer who is savagely beating a young shepherd boy (called Andrés), whom 
he accuses of stealing, to desist and to promise, on his 'honour', to pay the wages that the boy claims have been withheld from him. The farmer agrees to pay him once they get back to the farm. The knight, too naïve and obsessed with his own heroics to recognize the man's patent insincerity, identifies himself as "Don Quijote de La Mancha, righter of wrongs and friend of the downtrodden", bids them an airy "Goodbye", and canters off in triumph. There is a cut to a final vignette of the farmer, poised to beat the boy even harder than before. In the film's penultimate scene ('Chapter 9', 'Boy in the Forest'), Don Quijote encounters Andrés again. He is badly injured and supports himself on a crutch. He tells his 'liberator' that, thanks to his interference, he was almost beaten to death: "You are famous for destroying my life. I hate you." Confronted with the reality of the suffering he has caused, and recognizing the truth of Andrés's observation that it is he himself who is "the true enchanter", Don Quijote comes to his senses and decides to return home. In the final scene, we see him recognizing for what they are the ordinary things (the sheep; the plank over the creek; the windmill) that his imagination has previously transformed into fantastic chimeras, and able, for the first time, to appreciate their simple beauty.

Cervantes's Don Quijote is a book of multiple fictions enfolded, Russian-dolllike, one within another. This film's inclusion (as 'Chapter 8', 'Puppet Show at the Inn') of the famous Maese Pedro episode (Part II, Chapter 26 of the original) allows it to glance in that important direction: we see puppets watching a puppet play performed by smaller-sized puppets (crafted in a different style) manipulated by a puppet puppeteer and attacked by the puppet Don Quijote, who thinks that they are 'real'. In addition, the puppet play within the puppet film incorporates some elements of a story interpolated at another point within Cervantes's Don Quijote. This is the so-called 'Captive's Tale' (Part I, Chapters 39-41), which, in its turn, includes many autobiographical elements drawn from Cervantes's five-year period of captivity in Algiers. Cervantes's fictional captive speaks of meeting "a certain Saavedra" - Cervantes's second surname was Saavedra - in Algiers. The crusading Christian knight of the puppet show in the film, on whose behalf Don Quijote intervenes (destroying the little stage and marionettes in the process), is called Saavedra. Thus, through the transposition of this detail to this context (of puppet show within puppet film), Cervantes's love of interleaving fiction with fiction and both with history is fleetingly and aptly (if almost imperceptibly) honoured.

There are many other things to admire in Quixote: the performers are puppets but the camera technique (variety of shots), lighting, editing and sound values (the sound of the wind in the Windmills episode, for example) are worthy of a feature film. The sets are delightful: Don Quijote's house with its lime-washed walls and sparse furnishings is suitably austere; the backdrops of the miniature sets use photographic images of real Spanish landscape, softened to blend seamlessly with the sets themselves, which are made with real earth, grass, moss and leaves. The musical score (composed by Jeremy Yeremian) exploits soft guitar sounds to suggest Spain, recorders to evoke the historical period and North-African and Middle-Eastern instruments to conjure up the world of 
the Moors. The process of the making of Quixote is the subject of a fascinating twenty-minute film incorporated on the DVD as an Extra Feature.

In sum, Quixote, turns its miniature format to advantage and achieves a remarkably sensitive, intelligent, highly-concentrated and technically accomplished distillation of many essential facets of Cervantes's novel and character.

\section{Bibliography}

Quixote. Director: Steven Ritz-Barr, in cooperation with Hoku Uchiyama.

Musical Score: Jeremy Yeremian. Puppet Maker: Eugene Seregin. Classics in Miniature, Topanga, California, 2010.

Close, Anthony (1978), The Romantic Approach to 'Don Quixote'. Cambridge: Cambridge University Press 